\title{
APLICAÇÃO DE TRÊS PILARES DA MANUTENÇÃO PRODUTIVA TOTAL (TPM) NA CORREÇÃO DE FALHAS E MELHORAMENTO NO PROCESSO DE MANUTENÇÃO
}

\section{ARTIGO ORIGINAL}

MATA, Nayara Vieira da ${ }^{1}$

MATA, Patrick Augusto Vieira da ${ }^{2}$

MATA, Nayara Vieira da. MATA, Patrick Augusto Vieira da. Aplicação de três pilares da Manutenção Produtiva total (TPM) na correção de falhas e melhoramento no processo de manutenção. Revista Científica Multidisciplinar Núcleo do Conhecimento. Ano 04, Ed. 12, Vol. 04, pp. 47-72. Dezembro de 2019. ISSN: 24480959

\section{RESUMO}

Com a evolução do homem em manusear instrumentos e criar máquinas para bens de consumo próprio, houve a necessidade de mantê-los por mais tempo. Sendo assim, surgiu a Manutenção. Enquanto a população se desenvolvia, o conceito da manutenção também acompanhava esse desenvolvimento, chegando a um cenário competitivo entre as indústrias, onde foram produzidos/desenvolvidos vários conhecimentos e metodologias para alcançar a constante melhoria. Entre eles, está a Manutenção Produtiva total (TPM), que busca a falha e a quebra zero nos processos. Este estudo teve por objetivo identificar e fazer a correção das falhas, a fim de melhorar o processo de gerenciamento de uma empresa de prestação de serviços em ativos de refrigeração, o qual apresentou problemas ocasionados pela falta de organização, impactando diretamente na eficácia das realizações dos serviços

\footnotetext{
1 Graduação em Engenharia Mecânica.

${ }^{2}$ Graduação em Engenharia de Produção.
} 
programados, apresentando resultados bem abaixo dos previstos. Com a aplicação do conceito da TPM juntamente com os três pilares da eficiência que são manutenção autônoma, manutenção planejada e educação \& treinamento, obtiveram-se resultados na execução das atividades e nos indicadores IEP em 91 \% e TMOP 88\% , em pouco tempo de implementação, sendo possível corrigir e melhorar os serviços prestados pela empresa.

Palavras-chave: Manutenção, TPM, Três pilares.

\section{INTRODUÇÃO}

Com a evolução do homem surgiu a necessidade de meios para sua sobrevivência. Em consequência disso, o homem começou a desenvolver armas, ferramentas e posteriormente máquinas para seus bens de consumo. Ao observar que as mesmas não duravam o esperado, nasceu a manutenção, para suprir novas exigências que apareciam. Ela acompanhou a evolução industrial e foi crescendo conforme as mudanças na sociedade e o perfil de mercado. (TAVARES, 2005).

$\mathrm{Na}$ década de 70, ocorreu um grande marco na manutenção industria. Com a sua evolução, obteve-se um grau de importância diferenciado com fatores fundamentais às atividades. Nesta época, grandes potências industriais começaram a implementar planos de manutenção com propósito de garantia da competitividade na busca de maior eficiência da manutenção produtiva por meio de um sistema flexível, baseado no respeito individual e na participação dos empregados. (PINTO \& XAVIER. 2013)

A manutenção produtiva total (TPM) foi uma das grandes mudanças. Criada no Japão, em 1970 com um modelo de gestão abrangente, que trazia como objetivo a redução de custos, a elevação de sua produtividade, melhorias na qualidade dos produtos e serviços, garantia, assim, o desenvolvimento contínuo da competitividade da empresa. No Brasil, a TPM foi introduzida somente em 1981, por Nakajima e, desde então, muitas empresas vêm adotando esse tipo de manutenção como base de trabalho em equipe e autonomia, bem como uma abordagem de melhoria continua para prevenir quebras. (NAKAJIMA, 1989) 
O principal foco problemático da manutenção provém da falta de organização do processo. Vendo que o trabalho realizado está bem abaixo do serviço programado e do tempo disponível para realizá-lo. Isso evidencia tal fato, devido à falta de informações, falhas de comunicação e gerenciamento (homem hora, manutenção preventiva e corretiva).

A TPM é uma metodologia para dar eficiência na gestão de manutenção de empresas. Com seu processo bem estabelecido a empresa ganha credibilidade, competitividade e reconhecimento no seu campo de atuação, motivando e melhorando o desempenho de seus funcionários com planos de carreira e benefícios, levando excelência para os usuários finais, trazendo mais confiabilidade ao processo evitando transtornos e, consequentemente o aum.ento dos custos em relação a reparo, baseando-se na norma NBR16401. Isso implica a geração de novos empregos e contratos.

O intuito deste estudo é aplicar os conceitos da manutenção produtiva total (TPM), usando três pilares de sua estrutura, que são a manutenção autônoma, manutenção planejada, educação \& treinamento. Identificar, corrigir e melhorar o processo de manutenção, quantificar os resultados, e por fim, analisar as vantagens e desvantagens de uma empresa de prestação de serviço no segmento de refrigeração, no contrato de prestação de serviço do Aeroporto Internacional Tom Jobim.

\section{REFERENCIAL TEÓRICO}

\subsection{MANUTENÇÃO}

Conforme definição da NBR 5462 descrita na Associação Brasileira de Normas Técnicas (ABNT, 1994, p.37), manutenção é definida como "a combinação de ações técnicas e administrativas, incluindo as de supervisão, destinadas a manter ou recolocar um item em um estado no qual possa desempenhar uma função requerida".

A manutenção já teve como foco e prioridade manter e recauchutar as condições originais dos equipamentos. Muitas empresas ainda se utilizam dessa filosofia. Para Martins e Laugeni (2015), a manutenção não era vista como algo importante, apenas 
lembrada quando um equipamento ou máquina quebrava, porém hoje em dia esse quadro mudou. A missão dela é, segundo Pinto \& Xavier (2013, p.26), "Garantir a disponibilidade da função dos equipamentos e instalações de modo a atender a um processo de produção ou de serviço com segurança, preservação do meio ambiente e custo adequado". Segundo Pinto e Xavier (2013),o aumento da disponibilidade, qualidade do atendimento, segurança e otimização de custos passa pela redução da demanda de serviço, que tem as seguintes causas básicas: qualidade de manutenção, qualidade de operação, problemas crônicos, problema tecnológicos, serviços desnecessários e falta de disciplina.

Estas causas só serão resolvidas, eficazmente através de uma gestão estratégica, em que a manutenção precisa estar voltada para os resultados empresariais da organização, para, assim, deixar apenas de ser eficiente para se tornar eficaz, ou seja, não basta reparar o equipamento ou a instalação tão rápida quanto possível, mas sim, manter a função do equipamento disponível para a operação, reduzindo a probabilidade de uma parada não planejada. (PINTO \& XAVIER,2013).

De acordo com Pinto e Xavier (2013), o modo mais amplo de gestão, contempla o gerenciamento da rotina e a implementação de melhorias, onde empresas de classe mundial aplicam diversas ferramentas no seu cotidiano, dentre as quais se destacam o 5S e a TPM: Total Productive Maintenance. Mostrando o qual é grande o papel estratégico da manutenção nos tempos atuais, com a visão sistêmica do negócio e a mudança de paradigmas e de conceitos levarão a grandes inovações.

\subsection{QUALIDADE NA MANUTENÇÃO}

Pinto e Xavier (2013) e Xenos (2014) apresentam a Gestão pela Qualidade Total (GQT) ou Total Quality Managemente (TQM) como recurso administrativo que se originou na década de 50 nas indústrias japonesas e se tornou popular no Ocidente no início dos anos 80. Na atualidade a TQM é um componente do sistema gerencial da maioria das empresas, independente do seu porte, ela é uma ferramenta eficaz para alcançar a satisfação do cliente e a competitividade empresarial. 
Pinto e Xavier (2013) simplifica a TQM como a busca da melhoria contínua dos processos e o zero defeito através da relação entre os diversos segmentos da empresa. Os autores alertam para as resistências do processo de mudança de cultura, ainda mais forte nas atividades de manutenção que historicamente trabalhou para manter as condições e instalações criando um paradigma de estabilidade, que hoje está obsoleto. É preciso ser proativo e receptivo para se adequar o novo paradigma que é a cultura de mudança para quebra de referências que já tiveram sucesso no passado, mas já não se aplica.

Segundo Carpinetti (2016, p.44), para que a Gestão da Qualidade consiga atingir o aperfeiçoamento de seus processos, será necessário introduzir por meio da liderança a ideia na cultura organizacional da empresa. "Liderança é a capacidade de influenciar pessoas a fazer algo de boa vontade, a empregar seu talento na busca de resultados eficazes". Os líderes têm por objetivo tornar as pessoas envolvidas e comprometidas na busca de melhorias.

O sistema de qualidade é composto por diversos subsistemas que se interligam através de elos fortes e interdependentes, se assemelhando com o papel da manutenção, que tem como missão de garantir a disponibilidade de equipamentos e instalações, de modo que integração dos subsistemas atuem juntos para que o cliente interno principal tenha instalações de acordo com as necessidades da organização para atingir metas empresariais. (PINTO \& XAVIER,2013)

A falta de qualidade na manutenção provoca ações de retrabalho aumentando a demanda do mesmo modo ocorre na qualidade da operação. Uma ação incorreta gera consequência imediata e perda de produção, além de problemas crônicos e tecnológicos que são decorrentes de projetos não adequados, serviços desnecessários devido à sobrecarga na manutenção, excesso de manutenção preventiva acarretados por intervalos ou frequências mal definidas, falta de disciplina na execução dos serviços sem seguir os procedimentos elaborados.Todas essas ações geram uma demanda desnecessária acarretando na perda de qualidade no processo. (PINTO \& XAVIER, 2013) Pinto e Xavier (2013), conclui que o processo de 
qualidade implantado apenas na manutenção, traz melhorias para as instalações, mas tem alcance limitado, e, por isso é necessário a implementação em toda a organização, sem perder a vista para a manutenção, pois a mesma exerce uma forte influência nos demais segmentos.

\subsection{MANUTENÇÃO PRODUTIVA TOTAL}

Nakajima (1993) descreve que cada palavra da TPM possui um significado próprio: "T" significa "TOTAL", no intuito de eficiência global, no período de vida útil do sistema de produção e no envolvimento de todos os setores; "P" significa "PRODUCTIVE". Refere-se à busca do processo de produção até a linha máxima da eficiência, atingindo "zero acidente, defeito e quebra/falha", ou seja, a extinção de todos os tipos de perda até o nível zero; "M" significa "MAINTENANCE", isto é, manutenção no sentido abrangente, com o propósito do ciclo de vida útil do sistema de produção.

\subsubsection{OBJETIVOS DA TPM}

Conforme Tavares (2005), a finalidade da TPM é a renovação e o aperfeiçoamento da estrutura empresarial a partir da reformulação e melhoria das pessoas e dos equipamentos, com participação de todos os níveis hierárquicos e a mudança da postura organizacional. Para Pinto e Xavier (2013) o objetivo da manutenção produtiva total é a eficácia da empresa por meio da qualificação das pessoas, melhoramentos inseridos nos equipamentos, preparando pessoas, organizações aptas para conduzir as fabricas.

\subsubsection{IMPLEMENTAÇÃO DA TPM}

Conforme Suzuki (1994) para implantar a TPM é necessário seguir quatro etapas preparação, introdução, implantação e consolidação que se decompõem em dose passos.

Segundo Suzuki (1994) na etapa de preparação começa com a alta diretoria divulgando a decisão de introduzir a TPM e se difunde com a elaboração do plano 
mestre de desenvolvimento da TPM. Para Nakajima (1989) é necessário preparar um local propício para introduzir a TPM, através de cronogramas de atividades dos passos 1 a 5 para que não haja nenhuma surpresa no último momento.

Em seguida, a fase de introdução em qual todos os funcionários devem entender o porquê da implementação da TPM em sua empresa e estar certo de sua necessidade. (SUZUKI, 1994)

$\mathrm{Na}$ fase de implantação é posto em prática atividades que almejam atingir os objetivos do plano mestre, seguindo as ordens e os prazos das atividades dos passos 7 a 11 para ajustar as peculiaridades e individualidade dos integrantes da empresa, podendo executar atividades em paralelo. (SUZUKI, 1994)

$\mathrm{Na}$ etapa de consolidação a empresa oferece um prêmio de excelência em TPM, para homenagear os envolvidos nos resultados obtidos através da implementação. Os acionistas cujas companhias conquistaram o prêmio TPM comentam que: "TPM é sinônimo de lucratividade, sendo que a sua implementação propicia resultados significativos". (NAKAJIMA, 1994)

\section{ESTUDO DE CASO}

\subsection{PROCESSO ESTUDADO}

O processo de manutenção da empresa prestadora de serviços do Aeroporto Internacional Tom Jobim dá início com a elaboração do plano de 52 semanas, que tem a distribuição e divisão de um parque industrial de mais de 1.500 ativos, por criticidade, periodicidade e tempo previsto em minutos para execução de cada atividade. O plano é composto por equipamentos do tipo ar condicionado de janela, bebedouros, bombas, chilhers, cortina de ar, exaustores, fan coils de diversos modelos, geladeiras, ventiladores, torres, vaso de pressão, painéis elétricos e de automação, no qual cada equipamento é agrupado em frequências semanais, mensais, bimestrais, trimestrais, semestrais e anuais. 
A próxima etapa é a programação semanal, que é o espelho dos equipamentos descritos no plano de 52 semanas. A organização é feita internamente para visualização da empresa, antes das aberturas de O.S no máximo, no qual é o programa que o cliente tem visibilidade e faz análises para medições estabelecidas no SLA.

Em paralelo, as manutenções programadas, têm-se os atendimentos emergenciais e pontuais nos quais essas solicitações são acionadas pela Central de Controle de Operação e Manutenção(CCOM). A empresa possui uma equipe de plantonistas configurado em um (01) mecânico e um (01) auxiliar com escala de 12×36 horas para atender às demandas em todo o aeroporto, tendo suporte da equipe do comercial para algumas solicitações, onde o cliente estipula parâmetros no Acordo de Nível de Serviço para avaliar a efetividade do atendimento.

Dentro do SLA, o plantão de atendimento possui dois (02) indicadores de desempenho, o primeiro indicador é o tempo médio de atendimento de 45 minutos para dar feedback com a necessidade de uma ação corretiva ou solucionando o problema e o segundo é fechamento da S.S antes de completar 24 horas no sistema com o preenchimento correto.

\subsection{APLICAÇÃO DA METODOLOGIA DA TPM}

Buscando uma melhora qualificada no processo de manutenção da empresa, foram aplicados três pilares da produtividade. O primeiro é a manutenção autônoma, visando capacitar os plantonistas e a equipe de manutenção, para uma melhoria e mudanças garantindo maior produtividade e qualidade do serviço. No primeiro instante foi realizado um treinamento em campo explicando sobre a necessidade e importância da M.A (manutenção autônoma) para as equipes.

A equipe de atendimento que estiver no plantão estaria incumbida do primeiro ataque, fazendo um pré-diagnostico para ser posteriormente efetuada uma ação corretiva programada pela equipe comercial, diminuindo então o tempo de saturação e aumentando a vida útil do equipamento. O primeiro ataque seria baseado nos ativos

Disponível em: https://www.nucleodoconhecimento.com.br/engenharia-mecanica/tres-pilares-da- 
de maior índice de chamados vindas do CCOM (Central de Controle de Operação e Manutenção.

Abaixo um passo a passo apresentando a ação de plantonistas e comercial de acordo com cada etapa da manutenção autônoma.

\section{Primeira ação - PLANTONISTA}

Etapas: Limpeza inicial $\rightarrow$ Identificar fontes de contaminação e lugares inacessíveis $\rightarrow$ Verificação das condições básicas do equipamento: limpeza, lubrificação e reaberto.

\section{Segunda ação - COMERCIAL}

Etapas: Analisar os equipamentos apontados e Padronizar rotinas $\rightarrow$ Realizar ações corretivas $\rightarrow$ Sistematizar procedimentos $\rightarrow$ Gestão da manutenção autônoma.

Esse "cronograma" é dividido em duas partes, o primeiro é de responsabilidade da equipe plantonista, onde ficam responsáveis pelas etapas 1 a 3 , esses passos são basicamente itens de limpeza, verificação e identificação de locais e equipamentos de difícil acesso.

A equipe comercial tem como responsabilidade a padronização das rotinas de limpeza, verificação de componentes mecânicos e lubrificação de ações corretivas, sistematização do processo controlando ferramental e peças sobressalentes. A gestão da manutenção autônoma é dada com a dedicação de cada funcionário em manter os passos anteriores, coletar dados que permitam visualizar melhoria na disponibilidade e aprender a registrar e analisar dados dos equipamentos.

O segundo pilar para o progresso da empresa é a manutenção planejada, que consiste em detectar e tratar as anormalidades dos equipamentos antes que eles produzam defeitos ou perdas. O propósito principal é o desenvolvimento de um sistema que promova a eliminação de atividades não programadas de manutenção. 
Dentro da estruturação da mantenedora existe o setor de planejamento que tem como responsabilidade elaborar e ajustar o plano de 52 semanas e fazer programação semanal preventiva, mas é necessário ampliar o campo do planejamento, para que o mesmo tenha como objetivo não só as manutenções preventivas, mais sim planejar e controlar as corretivas e preditivas, de maneira que possa otimizar os recursos disponíveis e sem que haja riscos de quebras inesperadas, tendo como atividade gerar e manter atualizado o mapa de gestão visual do fluxo de manutenção, gerenciar a apropriação dos serviços executados, com aplicação de material e homem-hora, controlar e atualizar os padrões e procedimentos com suporte da engenharia e alertar à gerência sobre desvios encontrados no que foi programado.

O terceiro pilar para busca da melhora é a educação \& treinamento, que tem como o objetivo qualificar a mão de obra através de treinamento transmitindo aos participantes os principais conceitos necessários para a utilização desses pilares para o aperfeiçoamento do processo produtivo, para então buscar promover um sistema de capacitação para todos, tornando-os aptos para desenvolver suas atividades com segurança e qualidade.

\subsection{IDENTIFICAÇÃO DAS FALHAS}

Com o processo já estabelecido e descrito acima, foram apuradas falhas no fluxo de manutenção como a elaboração do plano de 52 semanas de forma genérica. São atribuídos o mesmo tempo de intervenção para equipamento de mesmo tipo, porém com características diferentes e também o desbalanceamento na montagem das semanas, ou seja, acarretando que haja semanas com mais ativos do que outras sem possuir um equilíbrio.

Este problema somado à negligência dos líderes em avaliar o que foi programado para remediar qualquer divergência, acaba gerando uma desorganização das atividades programadas, como se pode ver no gráfico 01 que o trabalho realizado está bem abaixo do serviço programado e do tempo disponível para realizá-lo , o que 
evidencia tal fato devido à falta de informações, falhas de comunicação e gerenciamento (homem hora, manutenção preventiva e corretiva).

Portanto causando brechas no processo de manutenção, pois os dados que chegam pelas ordens de serviços vão diretamente para software de controle da empresa. Se essas informações vierem de maneira contestáveis como, por exemplo, documentos com 100 por cento das horas executadas no qual tal atividade demanda 4 horas e o documento é apresentado com as tais 4 horas, sem nenhuma pendência, ou casos como atividades programadas em 2 horas e a mesma for executadas em 4 horas sem nenhuma justificativa plausível, e tem também a não execução da programação por alguma complicação encontrada pelo executante e o mesmo não informar o fato ocorrido, e ,por último, e pior caso, é a apresentação de ordem de serviço como trabalho realizado sem ao menos ir ao local para realizar tarefa.

Sem contar um grande potencializador que cerca a empresa que é o absenteísmo, nada mais que a ausência do funcionário no ambiente de trabalho seja por faltas ou atrasos, justificados ou não, afetando a eficácia e eficiência do sistema estabelecido.

Gráfico 01: Balanço das semanas programadas do mês de abril

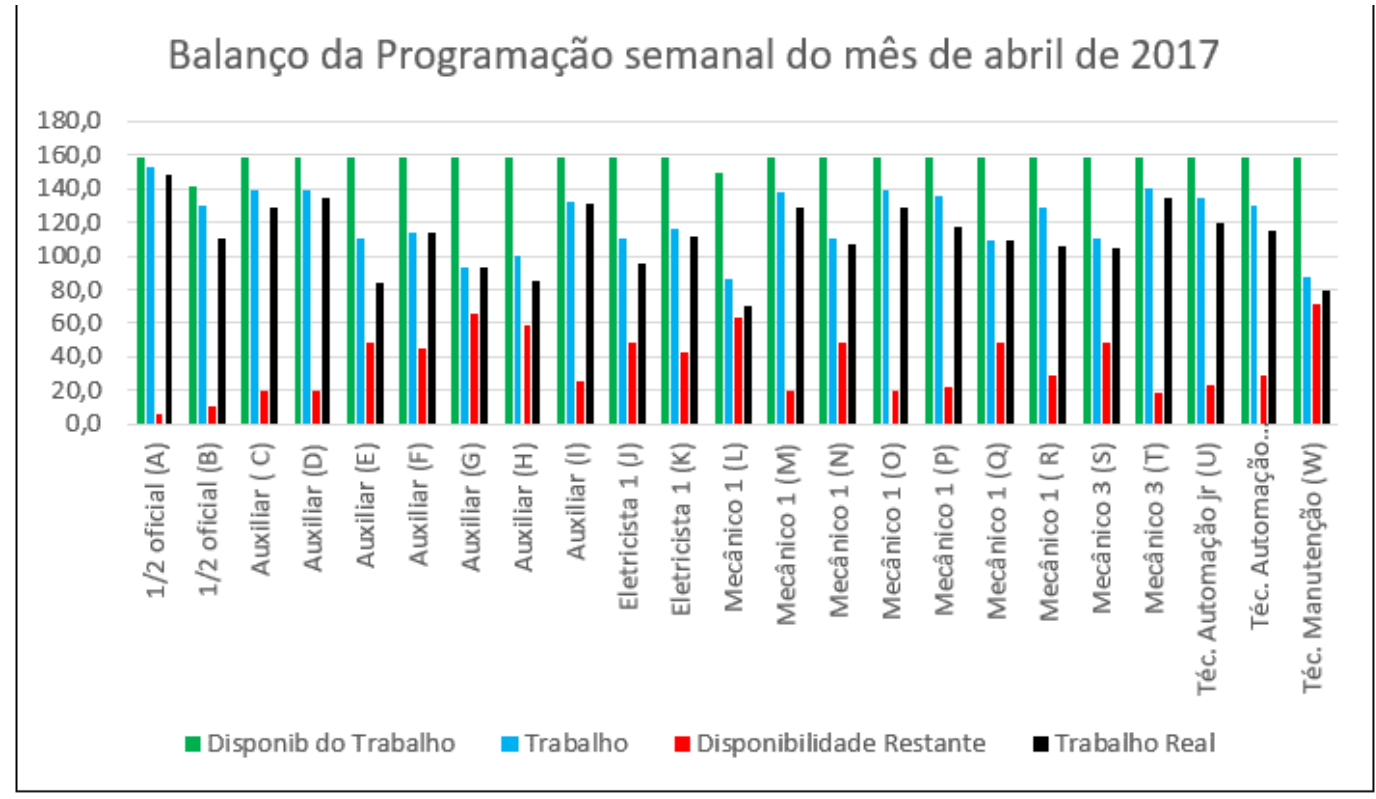

Fonte: Autor, 2017

Disponível em: https://www.nucleodoconhecimento.com.br/engenharia-mecanica/tres-pilares-damanutencao 
No gráfico, nota-se o balanço das programações semanais do mês de abril de um plano de 52 semanas do ano de 2017, este resumo é somatório das semanas 14 , 15,16 e 17 que fecham o mês, aqui tem a apuração de todas as atividades realizadas tanto programadas quanto extras, pode se perceber que o trabalho real (realizado) já somado com tempo de deslocamento está bem abaixo do trabalho (previsto) e do tempo disponível na semana que é um total de 44 horas, neste caso o total é de 158,4 horas já desconsiderando os feriados no período.

Os indicadores usados para verificação dos desvios no mês de abril, levando em consideração a aplicação de 23 colaboradores de mão de obra direta foram os seguintes: índice de eficácia do planejamento (IEP), cumprimento da programação das ordens de serviço (CPOS), taxa de ocupação de mão obra pela programação (TMOP) e índice de manutenção corretiva não programada (IMCNP).

No IEP mede-se a relação entre o total de hh aplicados nos serviços e o total de hh programados, memoria de cálculo:

Fórmula:

$\operatorname{IEP}(\%)$ Total de $\mathrm{HH}$ apropriados em OS executadas x 100 (1) Total de hh programado

Resultado:

$\operatorname{IEP}(\%)=\frac{2557}{2304} \times 100 \quad \operatorname{IEP}(\%)=111(2)$

Esse indicador avalia a qualidade do Planejamento, isto é, evidencia que a duração planejada dos serviços se confirma, após sua execução.

No CPOS mede a quantidade de OS executadas em relação as OS programados, memoria de cálculo:

Disponível em: https://www.nucleodoconhecimento.com.br/engenharia-mecanica/tres-pilares-da- 
Formula:

$$
\text { CPOS }(\%)=\frac{\text { Quantidade de OS programadas realizadas }}{\text { Quantidade de OS programadas + OS extras realizadas }} \times 100
$$

Resultado:

CPOS $(\%)=\frac{690}{615+129} \times 100 \operatorname{CPOS}(\%)=93(4)$

Esse indicador compara a quantidade de O.S realizadas dentro do intervalo de tempo predominado, ou seja, se elas realmente foram executadas dentro do prazo estabelecido, e se estão sendo desestabilizadas por demandas corretivas de caráter prioritário.

NA TMOP mede a capacidade do planejamento em manter a mão de obra ocupada ao longo do período, com programação planejada.

Fórmula:

$\operatorname{TMOP}(\%)=$ Total de hh programados $x 100$

Resultado:

$$
\text { TMOP }(\%)=\frac{2304}{3617} \times 100 \operatorname{TMOP}(\%)=64(6)
$$

Esse indicador pondera a aplicação de mão de obra em atividade.

NA IMCNP mede a relação de manutenções corretivas não programadas com total de horas de aplicação.

Disponível em: https://www.nucleodoconhecimento.com.br/engenharia-mecanica/tres-pilares-da- 
Fórmula:

$\operatorname{IMCNP}(\%)=\underline{\text { Horas de manutenção corretiva não planejadas realizada }} \times 100 \quad$ (9) Total de horas realizadas

Resultado:

$\operatorname{IMCNP}(\%)=\frac{184}{317} \times 100 \quad \operatorname{IMCNP}(\%)=58(10)$

Esse indicador relaciona e mede as manutenções corretivas não planejadas realizadas com total de horas aplicadas no período avaliado.

Analisando o gráfico e os resultados apurados pelos indicadores pode-se observar que há uma grande distorção na programação, onde não se tem um controle das manutenções corretivas e nem da aplicação correta de homem hora. Buscando solucionar essa falha foi elaborado um diagrama de Ishikawa, conforme figura abaixo, ferramenta utilizada para análise de dispersões no processo, para identificar causas e razões possíveis que fazem com que o problema ocorra.

Tabela 01 - Causa e efeito do baixo rendimento da programação.

\begin{tabular}{|c|c|c|}
\hline MATERIAIS & MÉTODOS & MÃO DE OBRA \\
\hline$\rightarrow$ Falta de peça de reposição & $\begin{array}{l}\rightarrow \text { Falta de qualidade na execução de serviço } \\
\rightarrow \text { Falta de abertura de OS para justificar H.H }\end{array}$ & $\begin{array}{l}\rightarrow \text { Preenchimento e entrega de O.S } \\
\rightarrow \text { Falta de abertura de O.S } \\
\rightarrow \text { Absenteísmo } \\
\rightarrow \text { Falta de informação } \\
\rightarrow \text { Capacitação técnica }\end{array}$ \\
\hline MÁQUINAS & MEIO AMBIENTE & MEDIDAS \\
\hline$\rightarrow$ Equipamentos obsoletos & $\begin{array}{l}\rightarrow \text { Acesso a casa de máquinas } \\
\rightarrow \text { Logística de acesso } \\
\rightarrow \text { Fatores de segurança do trabalho }\end{array}$ & $\begin{array}{l}\rightarrow \text { Tempo de deslocamento } \\
\rightarrow \text { Tempo previsto de manutenção } \\
\rightarrow \text { Falta de controle das } \\
\text { manutenções corretivas }\end{array}$ \\
\hline
\end{tabular}

RC: 42467

Disponível em: https://www.nucleodoconhecimento.com.br/engenharia-mecanica/tres-pilares-damanutencao 
Fonte: Adaptado de Ishikawa pelo Autor, 2017.

$\mathrm{Na}$ tabela pode-se identificar, através de 6 tipos diferentes de causas principais que afetam o processo (método, máquina, medida, meio ambiente, mão de obra e material). Na imagem é possível notar o que leva o trabalho realizado ficar bem abaixo do programado. Através de um brainstorm foi levantado que a mão de obra sofre com capacitação técnica, falta de informações, alto índice de absenteísmo, não realizar a abertura de ordem de serviço, não fazer o preenchimento adequado e não entregar a mesma na data programada.

Nas medidas se encontra o tempo de deslocamento aos equipamentos, tempo previsto de manutenção acima da necessidade e falta de controle das manutenções corretivas. No meio ambiente, fatores como acesso a casa de máquina, logística e segurança do trabalho. No método verifica-se a má qualidade na execução do trabalho, porém o retrabalho não é contabilizado, possuí negligência na abertura da ordem de serviço como complemento de homem hora. No campo, se lida com equipamentos obsoletos e, por fim, os materiais, onde há a deficiência do fornecimento pelo cliente, impactando em uma correção aonde poderia ser aplicada mão de obra de forma corretiva.

Em relação ao não cumprimento do tempo médio de atendimento foi efetuado um brainstorming com o supervisor dos Terminais, o encarregado do Terminal 1 e Píer Sule a equipe de plantão diurna com o objetivo de identificar as possíveis causas para o problema.

Foi levantado:

- Problemas de acessos às áreas restritas, mesmo com credenciamento;

- Diversos chamados simultâneos em locais distintos;

- Não compreendimento em atender o chamado com o resolve a solicitação;

- Identificação do ativo que atende a área. 


\subsection{MELHORAMENTO DO FLUXO DE MANUTENÇÃO}

Com a implementação dos pilares de eficiência pode se ver resultados imediatos na empresa, pois já nos primeiros dias é possível enxergar mudanças consideráveis no ambiente. Um dos primeiros pontos dessa ação foi na oficina mecânica de refrigeração conforme a figura 03 , onde foi realizado o primeiro passo da manutenção autônoma "limpeza inicial", foi arrumado e limpo, assim descartando todo material desnecessário, deixando o ambiente saudável, sem riscos de acidentes e agradável em realizar atividades no local.

Figura 01 - Antes e depois da Oficina mecânica do setor de refrigeração
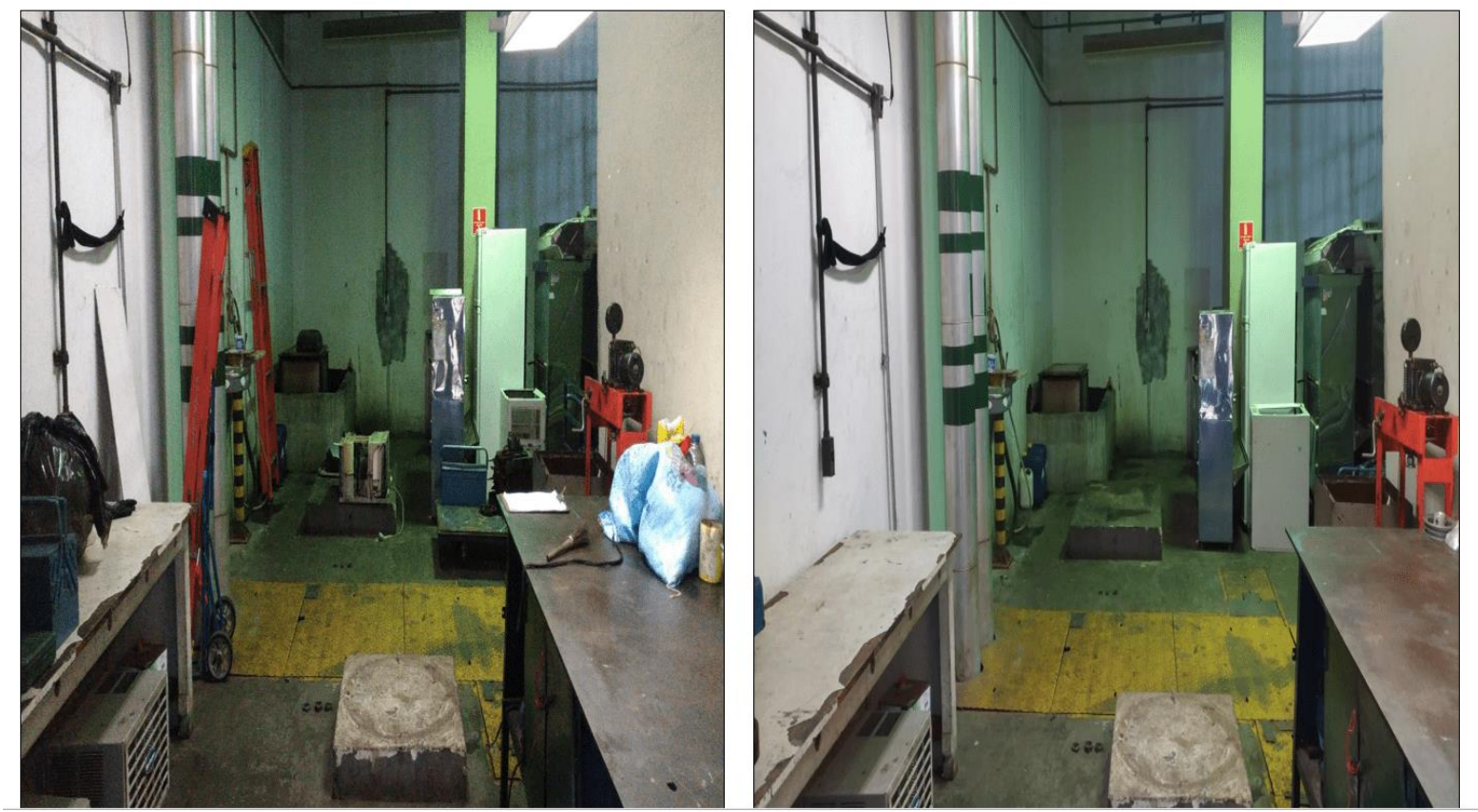

Fonte: Autor, 2017

$\mathrm{Na}$ figura 03 , encontra-se o antes e depois da organização na oficina, tendo a separação do ferramental e do material de consumo nas manutenções em lugares apropriados, promovendo um bem estar e conforto, uma boa impressão e organização. 
Figura 02 - Antes e depois da casa de bomba
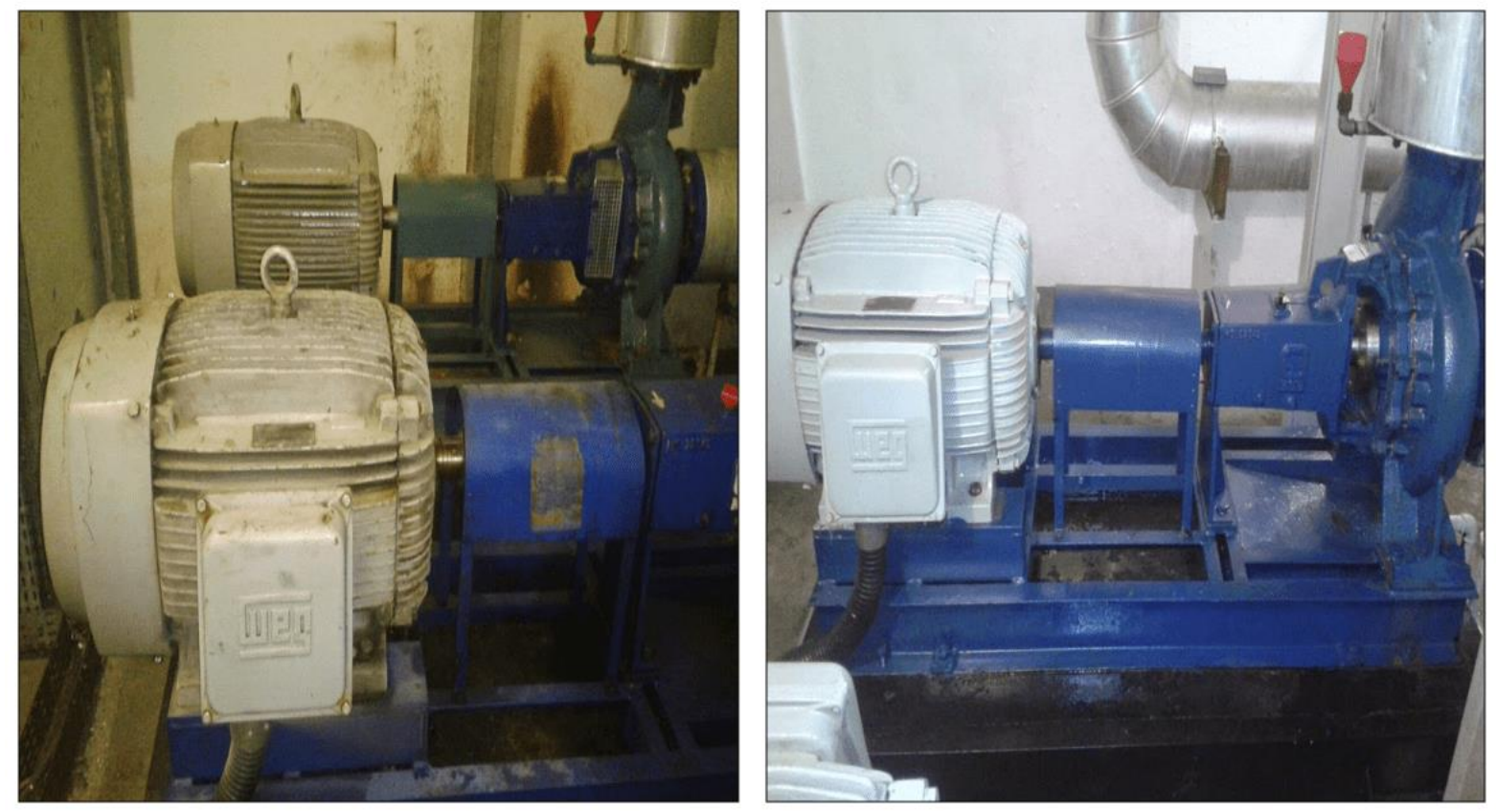

Fonte: Empresa, 2017

A figura 04, mostra o antes e depois da casa de bomba do setor bravo no Terminal 2 após a ação da manutenção. Com a implementação da M.A, os executantes passaram a ter mais responsabilidade e preocupação com os equipamentos, e começaram a puxar de suas líderes respostas para pendências em aberto que eram justamente esquecidas, pois o tempo de intervenções entre uma manutenção e outra são longos.

$\mathrm{Na}$ busca pelo aperfeiçoamento da gestão, foram direcionadas energias para parte de planejamento, em que foi reforçada a necessidade de um melhor controle das atividades, conforme a figura 05 de acompanhamento da programação foi dado início a reprogramação de atividades não executadas em semanas passadas. 
Tabela 02 - Acompanhamento da programação semana 43

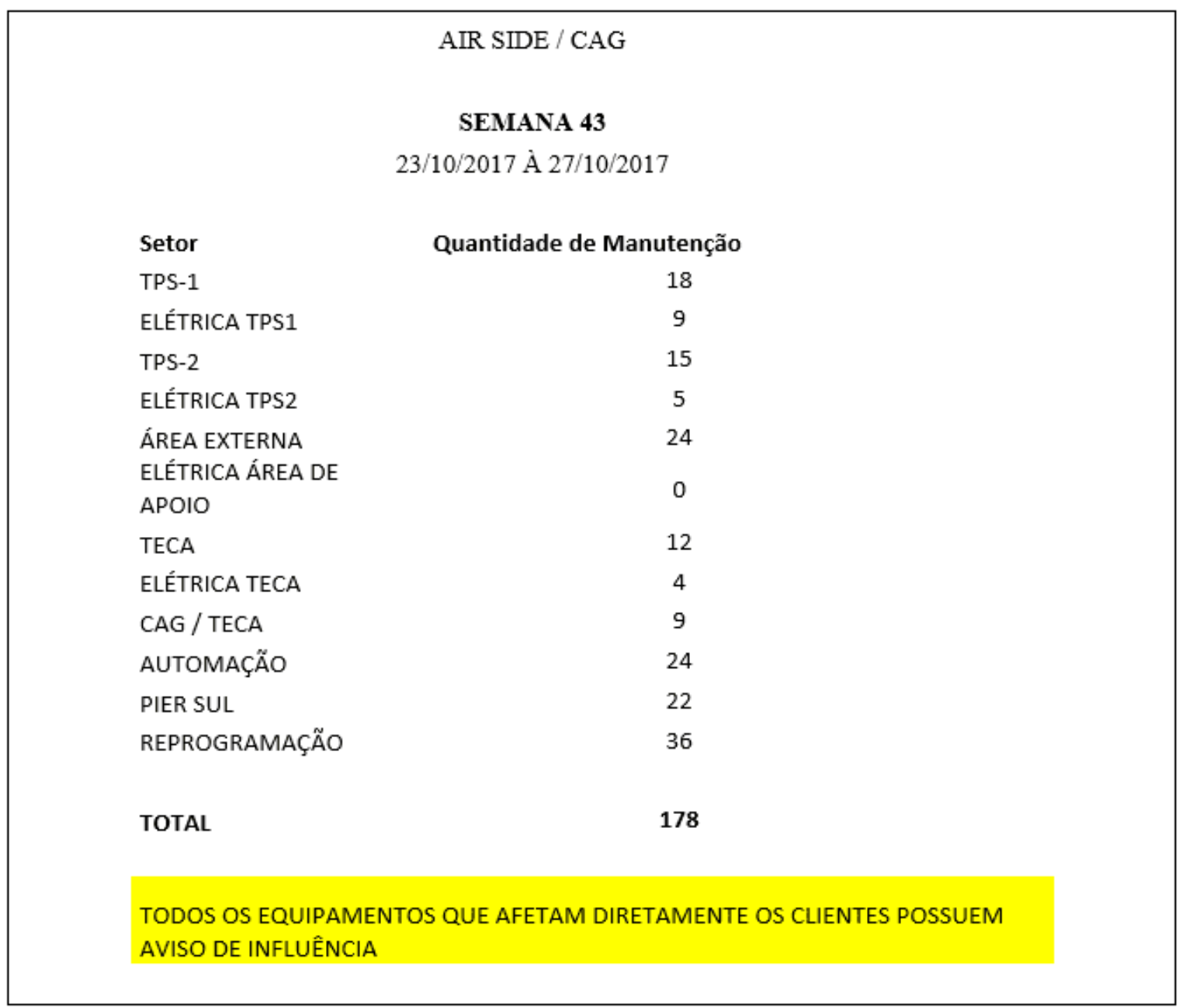

Fonte: Empresa, 2017

$\mathrm{Na}$ programação a cima, foram reprogramadas, de forma planejada, as atividades retroativas, não sendo encaixadas de forma aleatórias como era feito antigamente. Esse controle ajuda a identificar manutenções que são dependentes do apoio do cliente, como ,por exemplo, acessar as salas de companhias aéreas que são alugadas ou de órgãos federais, como a Receita e Polícia que não se pode acessar a todo o momento.

Assim como as reprogramações, as manutenções corretivas também entram no controle como atividades planejadas, com tempo previsto e alocação de mão de obra de acordo com a figura 06.

RC: 42467

Disponível em: https://www.nucleodoconhecimento.com.br/engenharia-mecanica/tres-pilares-damanutencao 
Figura 03- Acompanhamento da programação corretiva semana 44

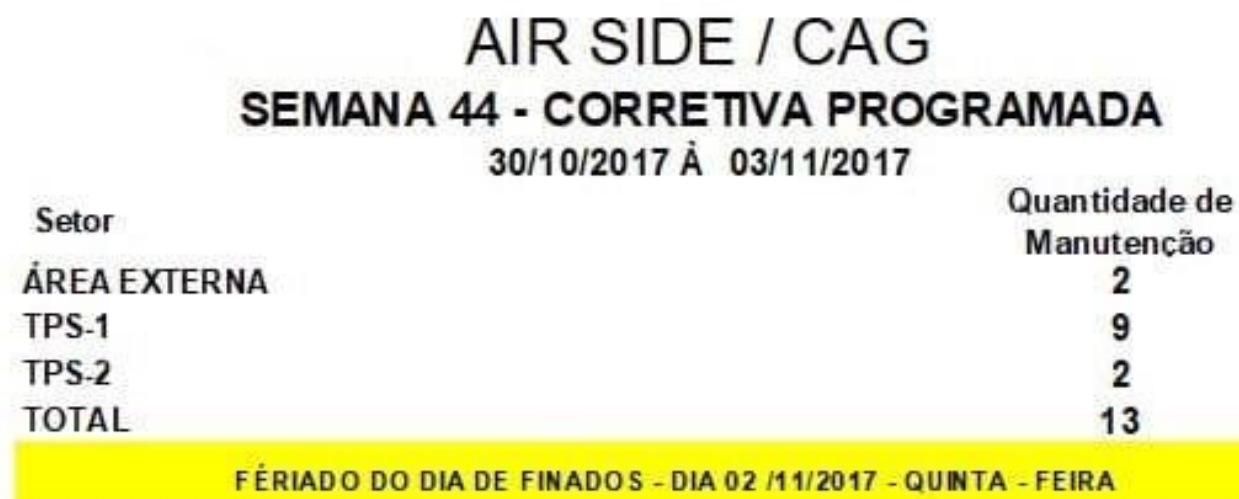

Fonte: Empresa, 2017

A figura 03 representa a programação da corretiva planejada, assim como aconteciam nas atividades reprogramadas de forma aleatória, as corretivas não tinham um planejamento prévio, simplesmente era executado desta forma, o que acarretava várias intervenções no mesmo equipamento, pois muitas vezes não se tinha todo material ou ferramental para execução essa atividade.

Em relação ao processo de manutenção, a gerência aproveitou a ascensão da equipe, e a mesma fez aquisição de cartões conforme a figura 07 para acompanhamento visual das atividades programadas, esses cartões possuem a logo da empresa, para mostrar o compromisso da mesma com seu processo e assim iniciando as correções dos problemas identificados. 
Figura 05 - Fichas de acompanhamento de manutenção

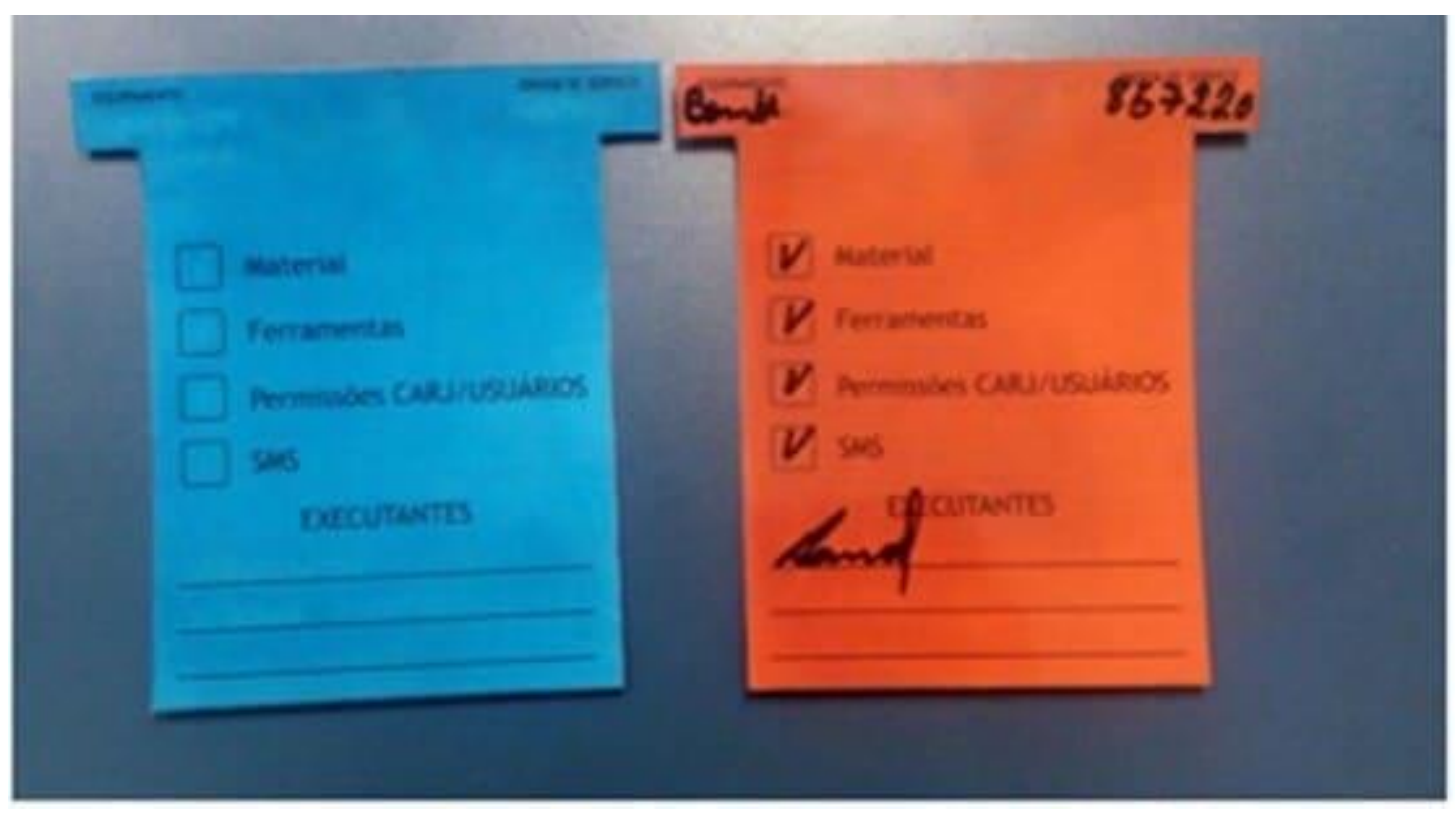

Fonte: Empresa, 2017

A configuração desses cartões de acordo com a imagem é azul e vermelha. Eles possuem as seguintes informações para serem preenchidas como: equipamento, setor, №. O.S, material, ferramenta, permissão (aviso de influência) e avaliação da segurança do trabalho. A ficha azul é pertinente à programação preventiva e a ficha vermelha representa as manutenções corretivas.

Esses TAG são devidamente preenchidos e pendurados em um quadro no qual são movimentados pelos encarregados, e essa gestão visual ajuda a acompanhar o quantitativo de manutenções previstas para a semana separado por cada setor, desta forma não se deixa passar nenhuma atividade sem realizar, que não seja apresentada na Figura 08, onde demonstra o quadro de acompanhamento das ordens de serviços. 
Figura 06- Quadro de acompanhamento das ordens de serviços programadas

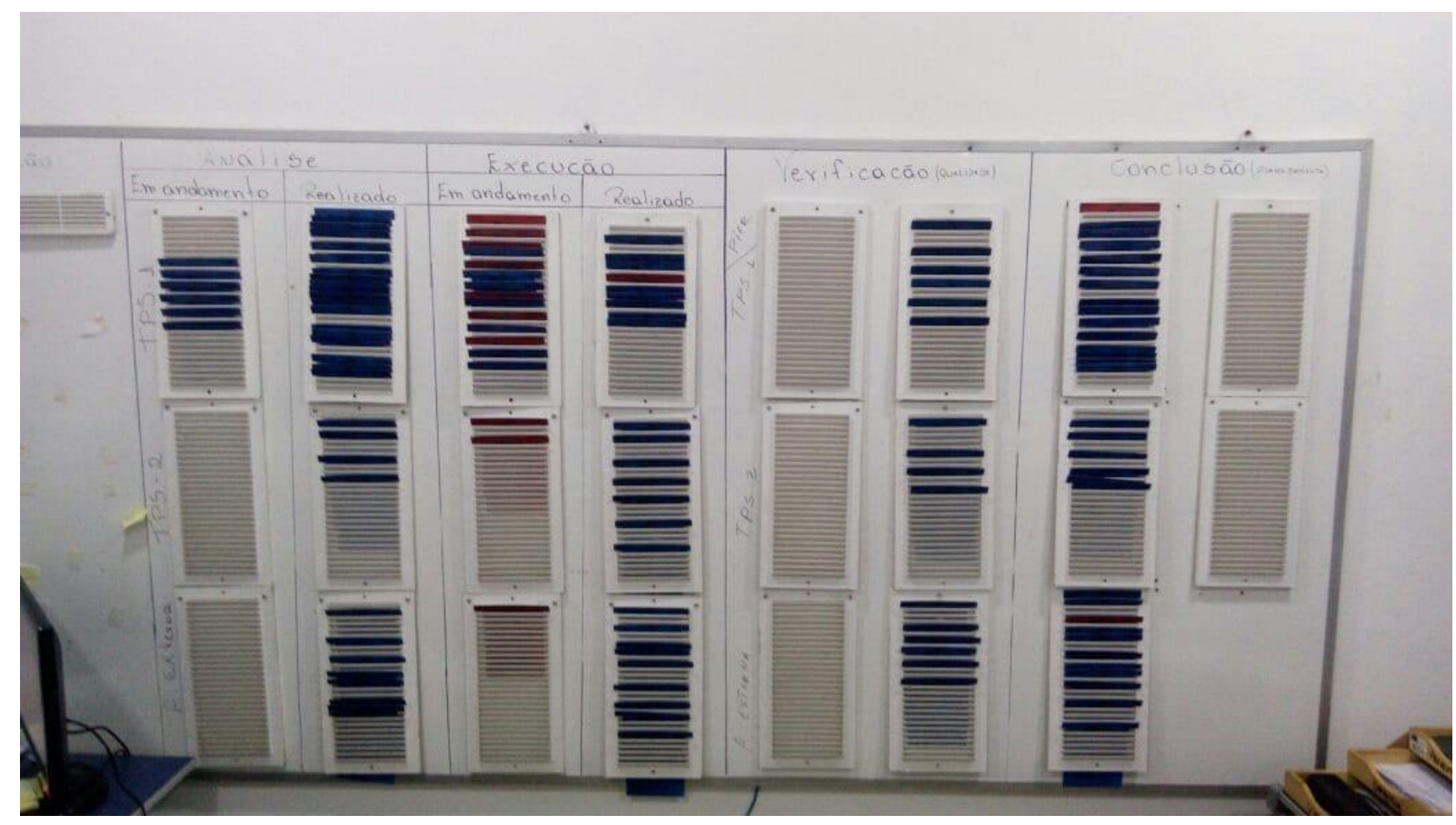

Fonte: empresa, 2017

Conforme a imagem, pode-se observar que o quadro obedece a quatro etapas para movimentação dos cartões.São elas: análise, execução, verificação e conclusão. Esse painel é montado de acordo com a programação semanal que é enviada toda a quartafeira, assim os líderes possuem a quinta e a sexta-feira, para fazer a avaliação do que foi programado para próxima semana.

Na etapa de análise, é feita a identificação das manutençõe em que podem ou não haver problemas em tais riscos, como risco a segurança do colaborador e/ou a dificuldade de acesso. Após essa classificação as O.S são passadas para parte realizada dentro da análise, até iniciar a semana, e na segunda-feira já se sabe quais atividades podem ser realizadas, desta forma os cartões são deslocados para a etapa de execução que possui a mesma configuração da análise que está em andamento e, então, é realizado, tão quanto os cartões com as tarefas concluídas são dados prosseguimento para verificação.

Disponível em: https://www.nucleodoconhecimento.com.br/engenharia-mecanica/tres-pilares-da- 
$\mathrm{Na}$ fase de verificação, é onde o setor da qualidade atua, juntamente com o suporte dos líderes de setor. Aqui é verificado o serviço realizado pelos colaboradores a nível de amostragem, a fim de avaliar e garantir um serviço com excelência para o cliente, após essa avaliação se obtém os resultados, se foi aprovado O.S passa para etapa de conclusão que é pertinente ao planejamento, se não, a mesma retorna como uma ação de retrabalho para o encarregado devolver para o mesmo executante corrigir e ser educado para não haver mais necessidade de ser refeita.

A última fase é a conclusão, aqui são recebidas todas as ordens de serviços aprovadas para receberem baixa no sistema e programar alguma ação corretiva oriunda da preventiva, desta forma estabelecendo um novo processo de acompanhamento e verificação das atividades. Dando seguimento no plano de melhoria contínua como a implementação do pilar de educação \& treinamento onde a empresa fez um esforço para adquirir junto à fiscalização um espaço para dar treinamento e capacitar os seus profissionais, a mantenedora fez um investimento em estrutura, eletrônicos e qualificação de profissionais para serem multiplicadores de conhecimento.

Os primeiros cursos foram para disseminar o pilar da manutenção autônoma, onde foi repassada para um grupo de 5 profissionais por turma. Logo abrindo módulos como certificações de NR's voltadas para segurança do trabalho, cursos de capacitação mecânica, como noções de instalação e manutenção de splits um dos equipamentos que mais apresentam falhas no processo devido a sua grande atualização no decorrer dos anos, ambos os módulos para o executante que concluir tem o certificado gerado pela empresa.

\subsection{QUANTIFICAÇÃO DOS RESULTADOS}

Mesmo com apenas dois meses de implementação dos pilares de eficiência, já se pode apurar uma melhora nos processos, abaixo tem o gráfico de controle do mês de outubro de 2017, que serve de comparação com o emitido em abril do mesmo ano. 
Gráfico 02: Controle da programação mês de outubro

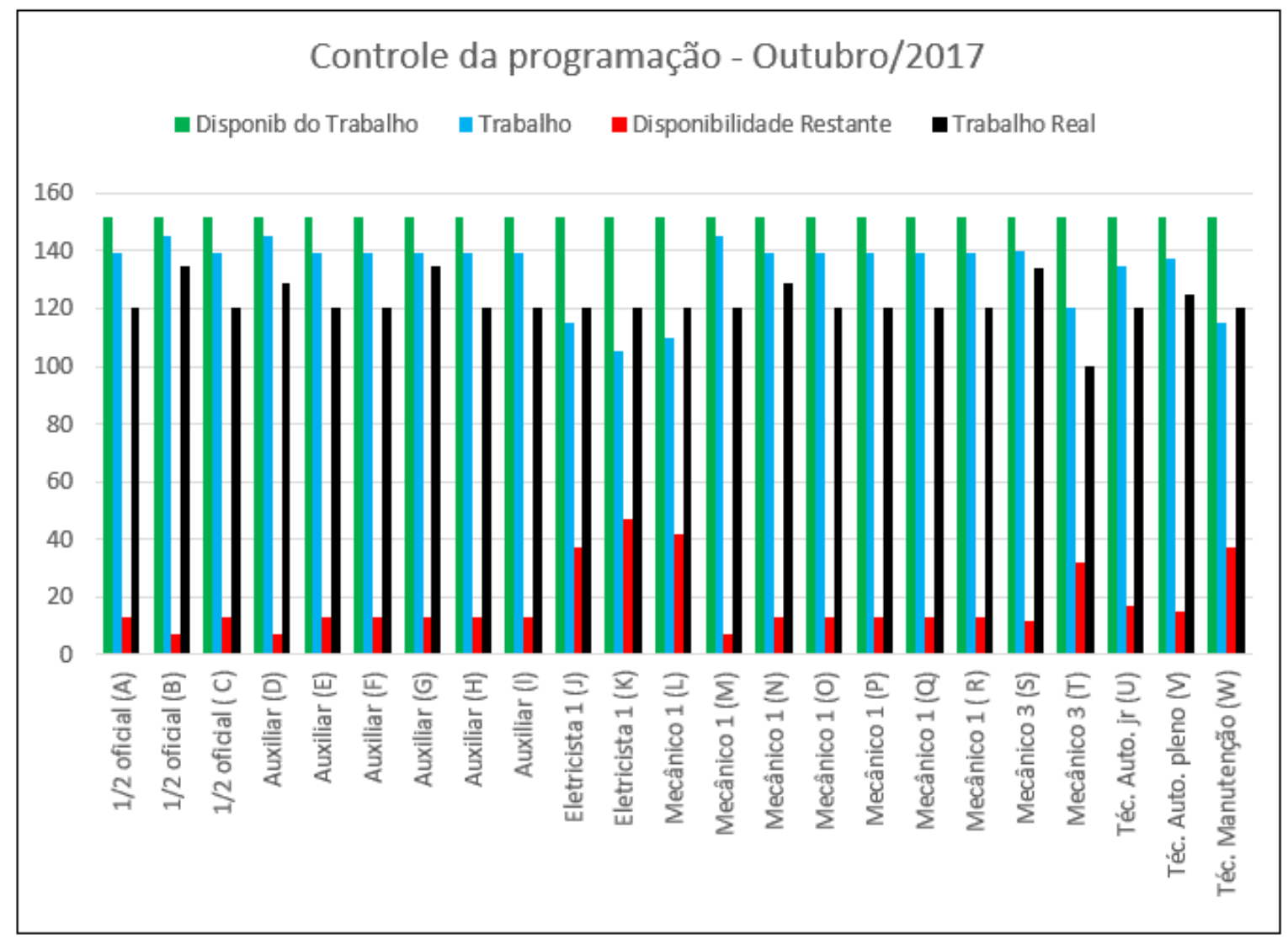

Fonte: Autor, 2017

No gráfico 02 , comparando com o de abril pode-se observar uma melhora no tempo de trabalho real (tempo retirado da mão de obra aplicada na O.S), que já se aproxima do trabalho (tempo programado para atividade) e tendo também o aprimoramento da equipe no qual teve promoção do auxiliar $C$ para $1 / 2$ oficial $C$ assim motivando a equipe. Esse comparativo serviu para que seja feito reajustes nos tempos de manutenções. Ainda em comparação com indicadores medidos em abril, foram apurados os seguintes resultados.

No índice de eficiência do planejamento teve uma redução em comparação com abril, porém os tempos de abril serviram como alerta, pois estava muito acima do tempo programado. 
Assim como identificado nas falhas esses tempos estão em processo de correção, como se pode observar no resultado do indicador.

$\operatorname{IEP}(\%)=\frac{2802}{3080} \times 100 \quad \operatorname{IEP}(\%)=91(11)$

No cumprimento da programação das ordens de serviço teve um aumento simbólico, porém é um sinal de melhora, devido aos esforços da empresa com a qualificação de seus colaboradores e a implementação da gestão visual, os cumprimentos da programação estão em sentindo positivo, pois não se deixa passar nenhuma atividade programada por conta de algum problema, assim como se pode concluir em relação ao resultado do indicador comparando-o com o do mês de abril.

$\operatorname{CPOS}(\%)=\frac{685}{705} \times 100 \quad \operatorname{CPOS}(\%)=97(12)$

Como IEP, a taxa de ocupação de mão obra pela programação teve uma melhora, pois com o ajuste nos tempos de manutenção, os equipamentos passaram a ter um planejamento com características factíveis de serem realizado.

TMOP (\%) $=\frac{3086}{3496} \times 100 \quad$ TMOP (\%) $=88(13)$

Depois da apuração dos indicadores, foi criado um gráfico com os comparativos do antes e depois da implementação dos pilares. 
Gráfico 03: Comparativo dos indicadores do mês de abril com outubro

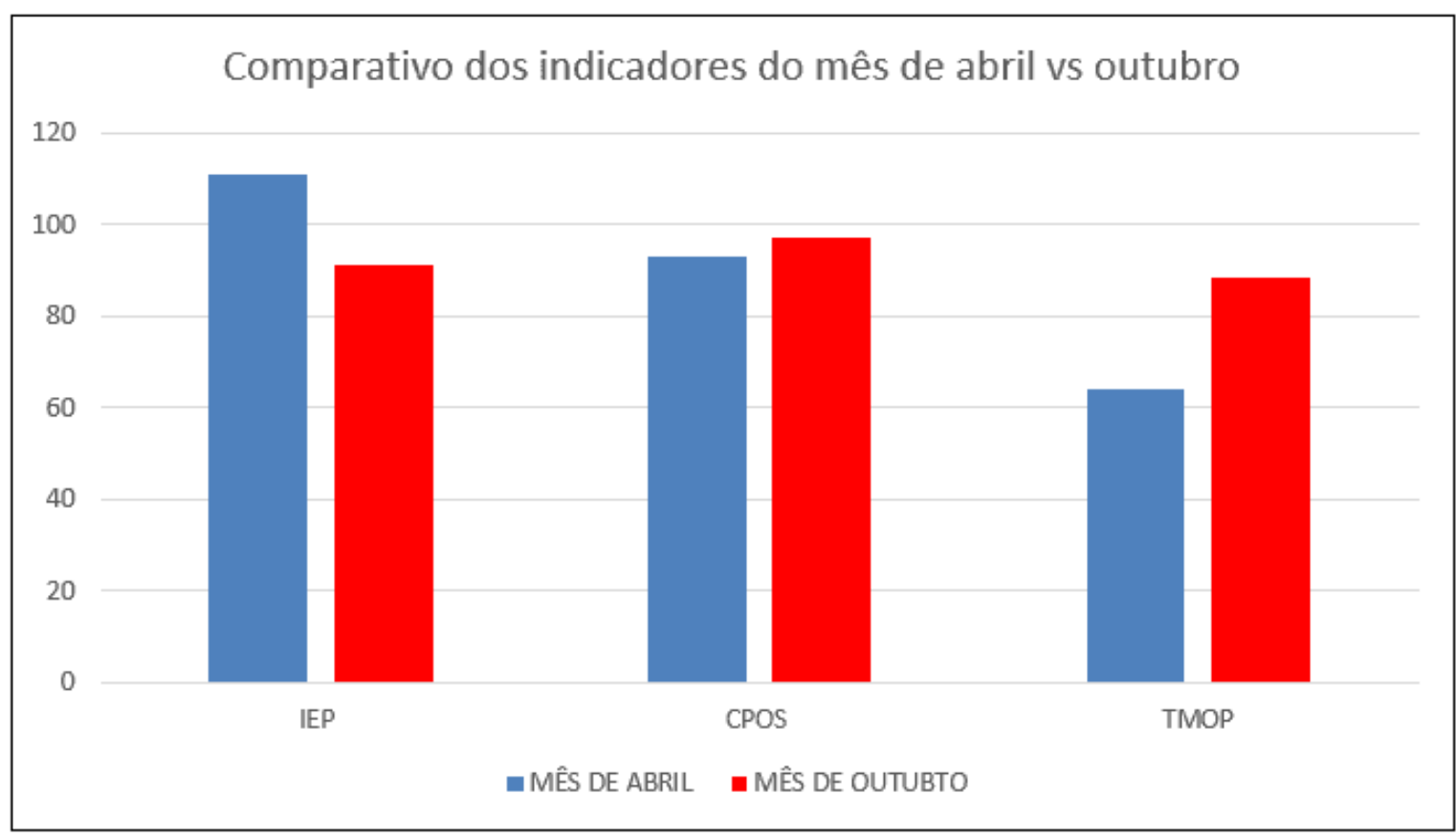

Fonte: Autor,2017

No gráfico 03, observam-se variações e uma perspectiva melhora dos processos vistos nos indicadores impostos na manutenção. Esse comparativo pode flutuar nos próximos meses devido o processo de adaptação dos pilares e a mudança cultural. Essa melhora não é apenas vista no campo de planejamento, pois o nível de confiabilidade da manutenção aumentou com o pilar da manutenção autônima no gráfico 04 , podem- se ver os quantitativos de máquinas operantes e inoperantes em um dos centros de manutenção. 
Gráfico 04: Operacionalidade do setor do Terminal 02

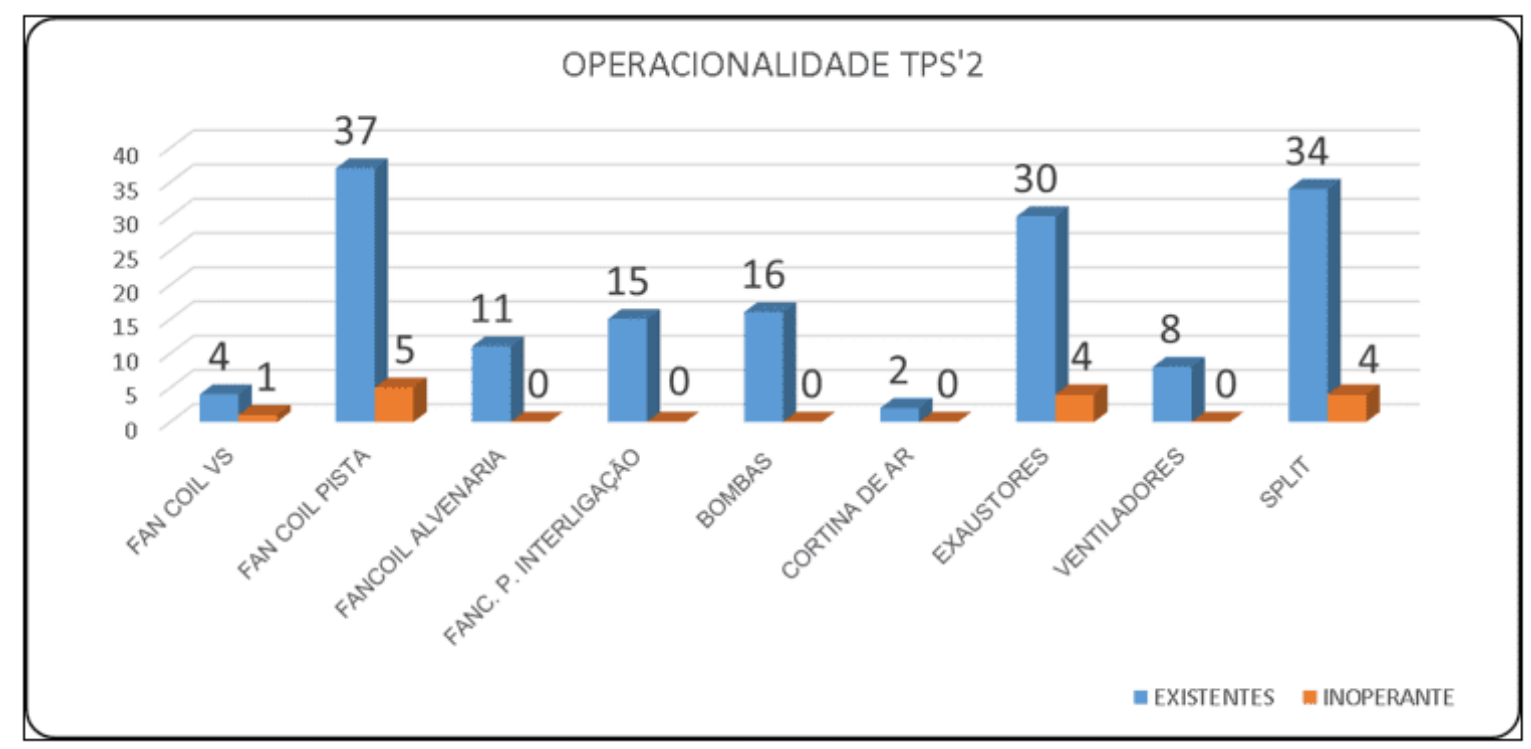

Fonte: Autor, 2017

Como pode ser visto no gráfico 04 , há os comparativos dos equipamentos existentes com inoperantes, dentro da central de manutenção do TP2, possui 14 máquinas sem funcionamento representando um total de 9 por cento, ou seja, o setor possui $91 \%$ das instalações operacionais. Em relação aos ativos com falhas todos tem um pedido de material feito para assim set ter 100 por cento da instalação

\subsection{ANÁLISE DE VANTAGENS E DESVANTAGENS}

Utilizando por meio da MPT e sua aplicação na empresa, pode-se adquirir como vantagens, o aumento da produtividade, uma grande redução de falhas, melhoria do ambiente de trabalho e menor risco de acidentes ocasionais, ganho da qualidade de atividades, otimização no fluxo de materiais, capacitação de pessoas promovendo o bem-estar, autonomia para ações pequenas, eficiência de equipamentos e seu uso até o fim definitivo, rotinas padronizadas e então uma inspeção e diagnostico de qualidade.

As desvantagens encontradas na implementação da TPM na empresa partem de a empresa possuir mais filias e os demais gestores entenderem da necessidade de

Disponível em: https://www.nucleodoconhecimento.com.br/engenharia-mecanica/tres-pilares-damanutencao 
implementar uma metodologia de melhoramento contínuo, assim como barreiras culturais na equipe, pela dificuldade de aceitação de qualquer tipo de mudança, além da autodisciplina de manter as etapas estabelecidas em cada fase. Porém suas vantagens ultrapassam qualquer dificuldade. A seguir tem a tabela 01 com síntese das analises e desvantagens.

Tabela 03 - Análise de vantagens e desvantagens

\begin{tabular}{|l|l|}
\hline VANTAGENS & DESVANTAGENS \\
\hline Aumento da produtividade; & $\begin{array}{l}\text { Entendimento da necessidade de } \\
\text { implementação da metodologia dos } \\
\text { gestores das demais filiais; }\end{array}$ \\
\hline $\begin{array}{l}\text { Redução de falhas; } \\
\text { Melhoria do ambiente de trabalho } \\
\text { e menor riscos de acidentes } \\
\text { ocasionais; }\end{array}$ & \begin{tabular}{l} 
Auto disciplina; \\
\hline $\begin{array}{l}\text { Ganho da qualidade de atividade; } \\
\text { Otimização do fluxo de pedido de } \\
\text { materiais; }\end{array}$
\end{tabular} \\
\hline $\begin{array}{l}\text { Otimização do fluxo de pedido de } \\
\text { materiais; }\end{array}$ & \\
\hline
\end{tabular}

Fonte: Autor,2017

Tabela 03 é a síntese das análises de vantagens e desvantagens.

\section{CONSIDERAÇÕES FINAIS}

Como em todas organizações de ramo de manutenção, a busca pelo melhoramento do processo é constante, o qual visam proporcionar serviços de qualidade, garantia de confiabilidade e manutenibilidade das instalações e estar preparado para manter no mercado, que se mostra cada vez mais competitivo. 
O vigente estudo teve como objetivo o melhoramento do processo de manutenção da empresa de prestadora de serviço de refrigeração com aplicação de três pilares da TPM, apesar de tão pouco tempo de implementação, foram obtidos resultados significativos na visibilidade do fluxo das atividades, planejamento e qualidade execução dos serviços.

Os objetivos específicos também foram alcançados com auxílio das ferramentas da qualidade e a aplicação da metodologia no qual foi possível identificar, corrigir e quantificar as falhas para assim ter o melhoramento no processo estabelecido.

$\mathrm{Na}$ primeira instância foram observados a forma que eram executadas as ordens de serviços planejadas, comparação do tempo previsto com o realizado, qualidade de serviço prestado, controle dos pedidos de materiais, se equipe aplicada havia comparecido e se atividade havia sido realizada de acordo com programado. Foi essencial a utilização das ferramentas histograma, brainstorming e diagrama de Ishikawa, pois com elas foram possíveis levantar e quantificar as causas para uma ação pontual.

$\mathrm{Na}$ segunda instância, após as análises das causas, foram sugeridos a implementação dos pilares de manutenção autônoma, manutenção planejada e educação \& treinamento para solucionar o desbalanceamento do plano de 52 semana que acarreta na falta de organização do processo, falta de informações, falhas de comunicação e gerenciamento (homem hora, manutenção preventiva e corretiva).

Desta maneira a utilização dos pilares de manutenção autônoma, manutenção planejada e educação \& treinamento, podem ser destacadas como ferramentas de aprimoramento de gestão, visando à busca pela falha zero e quebra de máquina zero. Portanto, a empresa obteve melhoras significantes com a utilização dessas ferramentas, deixando claro que o contínuo uso da aplicação das mesmas seria primordial para o crescimento, pois, para se manter competitiva no mercado atualmente, é necessária a busca de fatores que diferencie o seu processo dos demais concorrentes, de forma a garantir serviços com excelência dentro de suas limitações, 
redução de desperdícios e custos, maior margem de lucro, dentre diversas formas que possam garantir sua permanência no mercado.

\section{REFERÊNCIAS}

ABNT - ASSOCIAÇÃO BRASILEIRA DE NORMAS TÉCNICAS. NBR5462: Confiabilidade e Mantenabilidade. Rio de Janeiro, 1994.

CARPINETTI, Luiz Cesar Ribeiro. Gestão da Qualidade: Conceitos e Técnicas. 3. ed. São Paulo: Atlas, 2016.

MARTINS, P. G.; Laugeni, F. P. Administração da Produção. São Paulo: Saraiva. 3ํ․ ED,2015.

PINTO, Alan K., XAVIER, Júlio A. N. Manutenção Função Estratégica, Rio de Janeiro, Qualitymarck 4ํㅡㄹ., 2013.

SUZUKI, Tokutaro. TPM em Industrias de Processo (Tradução). Portland: Publishing Company Productivity Press, 1994. 388p

TAVARES, Lourival Augusto. 2005. A Evolução da Manutenção. Revista Nova Manutenção y Qualidade? No54.

XENOS, H. G. Gerenciando a Manutenção Produtiva - $2^{\mathrm{a}}$ Ed. São Paulo: Editora Falconi,2014

Enviado: Novembro, 2019.

Aprovado: Dezembro, 2019. 